\title{
Colonic Lipoma as a Cause of Colocolic Intussusception
}

\author{
Filipa de Sousa Costeira ${ }^{a}$ Margarida Gonçalves ${ }^{b}$ Cátia Esteves $^{c}$ Ana Rebelo ${ }^{d}$ \\ Carolina Leite ${ }^{c}$

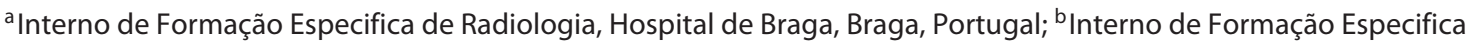 \\ de Gastroenterologia, Hospital de Braga, Braga, Portugal; 'Assistente Graduado de Radiologia, Hospital de Braga, \\ Braga, Portugal; ${ }^{d}$ Assistente Graduado de Gastroenterologia, Hospital de Braga, Braga, Portugal
}

Keywords

Colonic lipoma $\cdot$ Intussusception · Abdominal imaging

\section{Invaginação colocólica devido ao lipoma cólico}

\section{Palavras chave}

Lipoma cólico · Invaginação · Imagiologia abdominal

An otherwise healthy 55-year-old female patient with a family history of colon cancer presented to perform a total colonoscopy due to episodic abdominal pain and hematochezia for the past 1.5 months. It revealed an apparently pedunculated lesion of approximately $5 \mathrm{~cm}$ with superficial ulceration and friability in the transverse colon, which was primarily thought to correspond to a colonic neoplasia, mainly because of the presence of mucosal ulceration (Fig. 1). The lesion was biopsied.

Due to persistent and intense abdominal pain, she was admitted to the emergency department, and an abdomi-

karger@karger.com www.karger.com/pjg

Karger

GOPEN ACCESS
(C) 2020 Sociedade Portuguesa de Gastrenterologia Published by S. Karger AG, Basel

This article is licensed under the Creative Commons AttributionNonCommercial-NoDerivatives 4.0 International License (CC BYNC-ND) (http://www.karger.com/Services/OpenAccessLicense) Usage and distribution for commercial purposes as well as any distribution of modified material requires written permission.

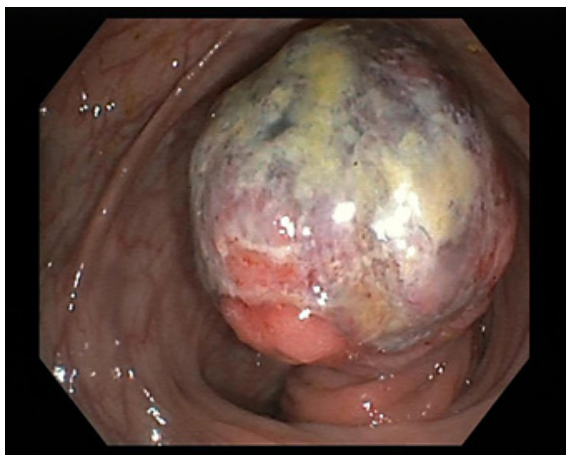

Fig. 1. Endoscopic image showing a voluminous pedunculated colonic lesion with superficial ulceration.

nal CT scan was performed, which showed a homogeneous lesion with fat density in the transverse colon lumen, measuring $5 \times 3,5 \mathrm{~cm}$, suggestive of a colonic lipoma (Fig. 2a). Moreover, proximal to the mass, a "donut"-like image was identified, establishing the diagnosis of colo- 

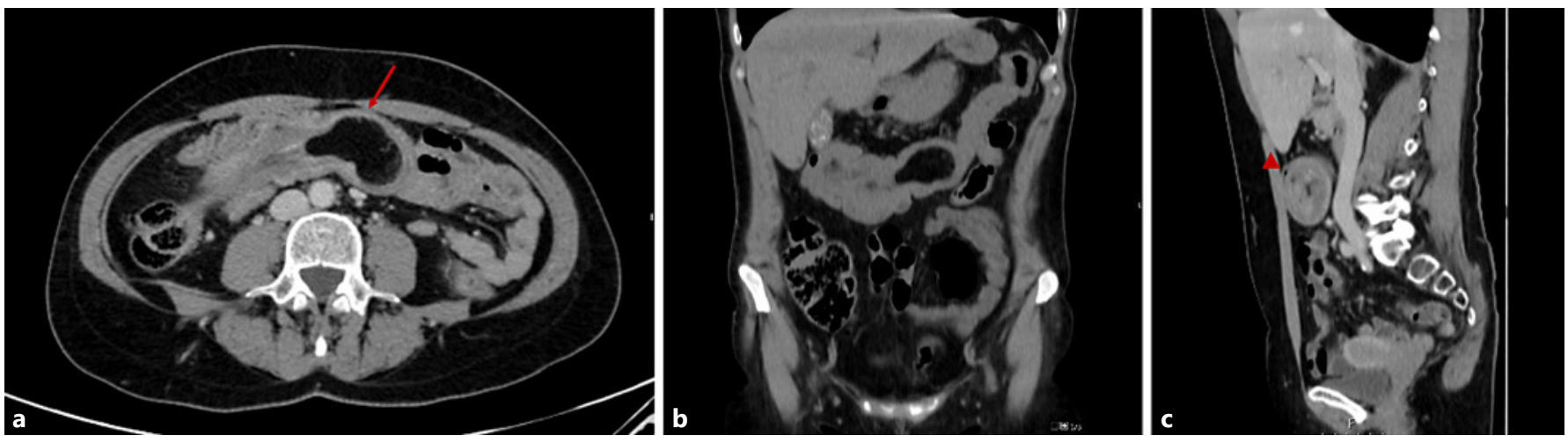

Fig. 2. CT image in axial (a), coronal (b), and sagittal (c) views showing an endoluminal homogeneous fat density lesion, located in the transverse colon (arrow), that corresponds to a colonic lipoma. Proximal to the mass, a "donut"-like image is identified (arrowhead), and the colonic lumen is filled with mesenteric fat and blood vessels. The findings are consistent with a colocolic intussusception.

colic intussusception due to the presence of a colonic lipoma (Fig. 2b, c). There were no bowel distension, hidroaeric levels, or other evidence of obstruction. The laboratorial study was unremarkable.

The patient was submitted to a right hemicolectomy with no complications and full recovery. The histopathological study confirmed the diagnosis of lipoma.

Colonic lipomas are rare, benign tumors with an incidence of $0,2-4,4 \%$. In approximately $90 \%$ of the cases, they arise from the submucosa but may extend into the muscularis propria; $10 \%$ are subserosal [1]. Lipomas can arise in any part of the colon, but the most common sites are the cecum, ascending colon, and sigmoid colon, in decreasing frequency [2]. They usually occur between the fifth and sixth decades of life and are often incidental findings during colonoscopy or surgery, as most are asymptomatic [3].

Symptomatic colonic lipomas may cause abdominal pain, obstruction, and intussusception or be complicated by hemorrhage. Most cause chronic symptoms due to progressive growth and are usually symptomatic when their size exceeds $2 \mathrm{~cm} \mathrm{[4].}$

Endoscopically, they typically present as smooth, slightly yellow polyps, with broad-based attachment and intact or eroded overlying mucosa [2]. On CT, they have low attenuation values, which suggests a lipomatous nature [5].

Intussusception of the bowel is defined as the telescoping of a proximal segment of the gastrointestinal tract within the lumen of the adjacent segment. It is common in the pediatric population but is a rare condition in adults, accounting for $5 \%$ of all intussusceptions [6]. Up to $20 \%$ are idiopathic, with no identification of a lead point. Most cases are secondary and can be caused by organic lesions, such as inflammatory bowel disease, postoperative adhesions, benign and malignant lesions, or metastatic neoplasms. It can also be iatrogenic due to the presence of intestinal tubes, jejunostomy feeding tubes, or after gastric surgery [7].

Most intussusceptions occur in the junctions between freely moving intestinal segments and retroperitoneal or adhesionally fixed segments. The majority of intussusceptions occurring in the large bowel have a malignant etiology, including primary tumors such as adenocarcinoma, lymphoma, and metastatic disease, primarily from melanoma. Due to this fact, the reduction of a colonic intussusception is highly controversial, and a surgical approach is favored [8].

\section{Statement of Ethics}

The authors declare that all ethical procedures were followed. The patient signed a written consent, allowing use and divulgation of clinical information and images.

\section{Disclosure Statement}

The authors have no conflicts of interest to declare. Moreover, they are aware that the manuscript's copyright belongs to GE Portuguese Journal of Gastroenterology. 


\section{References}

1 Vecchio R, Ferrara M, Mosca F, Ignoto A, Latteri F. Lipomas of the large bowel. Eur J Surg. 1996 Nov;162(11):915-9.

2 Shi L, Zhao Y, Li W. Endoscopic resection of a giant colonic lipoma with endoloop-assisted unroofing technique: A case report. Medicine (Baltimore). 2018 Jun;97(23):e10995.

3 Michowitz M, Lazebnik N, Noy S, Lazebnik R. Lipoma of the colon. A report of 22 cases. Am Surg. 1985 Aug;51(8):449-54.
4 Mohamed M, Elghawy K, Scholten D, Wilson $\mathrm{K}$, McCann M. Adult sigmoidorectal intussusception related to colonic lipoma: A rare case report with an atypical presentation. Int J Surg Case Rep. 2015;10:134-7.

5 Sreevathsa MR, Nishnata K, Bhavyadeep K. A Management Dilemma - Submucosal Colonic Lipoma (A Case Series). Clin Surg. 2018;3: 2268 .
6 Rutherford CL, Alkhaffaf B, Massa E, Turner P. Colo-colic intussusception secondary to lipomatous polyp in an adult. BMJ Case Rep. 2013 Mar;2013(March):bcr2012008037.

7 Azar T, Berger DL. Adult intussusception. Ann Surg. 1997 Aug;226(2):134-8.

8 El-Sergany A, Darwish A, Mehta P, Mahmoud A. Community teaching hospital surgical experience with adult intussusception: study of nine cases and literature review. Int J Surg Case Rep. 2015;12:26-30. 